\title{
Urgences
}

\section{Bernard Demers, Le Zérocycle, Montréal, Québec/Amérique, coll. " Littérature d'Amérique ", 1989, 144 p.}

\section{Marie Bélisle}

Numéro 22, janvier 1989

Octet

URI : https://id.erudit.org/iderudit/025507ar

DOI : https://doi.org/10.7202/025507ar

Aller au sommaire du numéro

Éditeur(s)

Urgences

ISSN

0226-9554 (imprimé)

1927-3924 (numérique)

Découvrir la revue

Citer ce compte rendu

Bélisle, M. (1989). Compte rendu de [Bernard Demers, Le Zérocycle, Montréal, Québec/Amérique, coll. " Littérature d'Amérique ", 1989, 144 p.] Urgences, (22), 58-67. https://doi.org/10.7202/025507ar d'utilisation que vous pouvez consulter en ligne.

https://apropos.erudit.org/fr/usagers/politique-dutilisation/ 


\section{deliveline}

\section{Bernard Demers, Le Zérocycle, coll. "Littérature d'amérique", Montréal, Québec/Amérique, 1989, $144 \mathrm{p}$.}

Raymond Queneau, Exercices de style, [1947], coll. «Folio», Paris, Gallimard, (1982), 158 p.

En 1947, Raymond Queneau publiait Exercices de style: une brève histoire «racontée» quatre-vingt-dix-neuf fois, de quatrevingt-dix-neuf manières différentes. Quarante ans plus tard, Bernard Demers, entreprend le projet d'écrire quatre-vingt-dix-neuf autres variations de cette anecdote du zazou dans l'autobus. D'où le sous-titre du Zérocycle: ou les exercices de style à la manière de Queneau. En fan de Queneau, j'ai donc entrepris la lecture avec enthousiasme.

Heureux(?) hasard, je venais tout juste de relire les Exercices de style, de me régaler (encore) de cette démonstration magistrale de l'efficace de la contrainte. Quatre-vingt-dix-neuf détournements divers (pervers?) de la narration: figures de rhétorique, contraintes oulipiennes, pastiches, etc. Lecture obligatoire pour tous ceux et celles qui croient qu'une histoire se raconte une fois pour toutes (et qu'il y a une «bonne» façon de la raconter); au mieux, ils seront convaincus du contraire (et plutôt quatre-vingt-dix-neuf fois qu'une), au pire, ils perdront deux heures de leur temps précieux en s'amusant un peu.

Heureux hasard, disais-je que ces lectures presque simultanées des Exercices de style et du Zérocycle? Je ne sais trop. La comparaison était devenue inévitable. Comment dès lors les textes de Demers se défendraient-ils devant (derrière?) ceux de Queneau? Comment, surtout, le projet de Demers se justifierait-il?

Pour ce qui est des textes, Le Zérocycle se défend plutôt bien. Quelques trouvailles: les versions «interactives» où le lectreur doit 
décoder lui-même l'anecdote (charade, mots-croisés, rébus, traductions en braille, morse, sourd-muet, sémaphore, etc.), le texte intitulé «Pages roses" où se bousculent les expressions latines, le "Sémiotique», la "Bureaucratique», celui entièrement composé de citations (à un fragment près), le «Catalogue» des objets présents dans l'histoire, etc. Quelques faiblesses (de conception et/ou d'exécution): le texte «Dislexique» où les $d$ et $b$, et les $p$ et $q$, sont intervertis, celui qui réorganise de façon aléatoire les mots du texte de Queneau, l'“Amnésique» composé essentiellement de questions, le “Téléphonique», l'“Abrégé» rappelant un peu trop la version «Apocopes» de Queneau, etc. Bref, du meilleur et du pire mais, certainement, de quoi s'amuser autant qu'avec Queneau.

Pour ce qui est du projet, c'est moins simple. «ll ne s'agit pas de commettre un plagiat transposé, en écrivant un nouveau récit selon les variations d'origine, ou en créant de nouvelles variations sur une nouvelle histoire", écrit Demers dans son avant-propos. Stricto sensu, c'est réussi: le Zérocycle n'est pas un plagiat transposé. Mais n'est-ce pas (un peu tout de même) un plagiat tout court? Un des principes de Queneau (tels que décrits dans l'At/as de littérature potentielle) ne veut-il pas que «La contrainte idéale ne suscite qu'un texte ''? Mais, soyons honnêtes, ce n'est pas le respect d'un principe qui fait les bons ou les mauvais livres. Ne sautons pas trop vite aux conclusions et considérons Le Zérocycle pour ce qu'il est: ni le résultat d'un projet original ni un plagiat, mais un supplément aux Exercices de style.

On attendra, maintenant, que Demers nous démontre qu'il peut non seulement réaliser honorablement un "exercice» conçu par quelqu'un d'autre, mais élaborer un projet littéraire qui lui soit propre.

\section{Marie Bélisle}

1. Oulipo, Atlas de littérature potentielle, coll. «Idées»,Paris, Gallimard, 1981, p. 63. 